\title{
AMÉRICA LATINA, EXPERIÊNCIAS SOCIALISTAS E EDUCAÇÃO
}

\author{
AMÉRICA LATINA, EXPERIENCIAS SOCIALISTAS Y EDUCACIÓNLOS
}

\section{LATIN AMERICA, SOCIALIST EXPERIENCES AND EDUCATION}

DOI:: https://doi.org/10.9771/gmed.v13i3.47461

\author{
Fernando Correa Prado ${ }^{1}$ \\ Giselle Modé Magalhães² \\ Mario Mariano Ruiz Cardoso ${ }^{3}$ \\ Hélio da Silva Messeder Neto ${ }^{4}$
}

Em um dos ensaios que compõe sua Defensa del marxismo (1929), José Carlos Mariátegui (1988) diz em certo momento: "enquanto o capitalismo não tiver sido destruído definitivamente, o cânone de Marx segue sendo válido". Não por acaso este cânone e a tradição daí derivada se enraizou - e segue presente de diferentes formas por todo o mundo, e na América Latina e Caribe deixou uma gama profunda de história, com suas expressões, mais ou menos unitárias e coerentes, em termos teóricos e políticos. Analisar essa história é tarefa fundamental para a compreensão transformadora da realidade atual, sobretudo se consideramos o eurocentrismo, com suas fortes influências sobre o pensamento crítico no Brasil, e também se pensamos que mesmo dentro da tradição marxista aberta às experiências de luta em Nuestra América ainda falta muito a conhecer. Este número da Germinal busca contribuir um pouco neste sentido, trazendo textos que articulam a educação com a América Latina e Caribe e suas experiências socialistas.

Isso remete à outra frase-síntese de outro marxista: Walter Benjamin. Em sua tese VI Sobre o conceito de história (BENJAMIN, 2008), sentencia tão precisamente: “também os mortos não estarão em segurança se o inimigo vencer". De fato diversas experiências de luta pela construção do socialismo nas especificidades da América Latina e Caribe foram vencidas, e os vencedores - burguesia e suas frações, imperialismo e suas expressões - trataram de enterrar suas histórias, negando a existência inclusive de seus mortos. Contudo, outras tantas experiências foram vitoriosas, souberam resistir, se enraizar e transformar a realidade da classe trabalhadora, tendo sempre a educação como um dos pilares da luta revolucionária.

Nesse número da Germinal, assumimos uma pequena parte dessa tarefa de refletir sobre as experiências da classe trabalhadora na América Latina, imbuídos pelo clima bastante estimulante que nos chega nesse 2021 pelo centenário do patrono da educação brasileira, o educador nordestino Paulo Reglus Freire. Nesse sentido, esse número inclui também textos sobre Paulo Freire que conectam a obra desse que 
é o brasileiro mais estudado pelo mundo com a dinâmica das lutas socialista latino-americana, em especial da Revolução Cubana. Um 2021 que comemoramos o $60^{\circ}$ aniversário da finalização da Campanha de Alfabetização da ilha socialista e recebemos a notícia da vitória no Chile de um candidato a presidente que representou a vontade popular de enterrar a política neoliberal do capital, que também se manifestou na educação, que assolou e corroeu as condições de vida da classe trabalhadora da pátria do socialista Salvador Allende.

A coordenação do dossiê América Latina, experiência socialista e educação ficou a cargo dos Professores Fernando Correa Prado da Universidade Federal da Integração Latino-Americana, da Professora Giselle Modé Magalhães da Universidade Federal de São Carlos, o Professor Hélio da Silva Messeder Neto da Universidade Federal da Bahia e o Professor Mario Mariano Ruiz Cardosos da Universidade Federal dos Vales do Jequitinhonha e Mucuri.

Abrimos este número da Revista Germinal: marxismo e educação em debate na seção Entrevista, dialogando com Micaela Ovelar e Catherine Murphy, integrantes do The Literacy Project5 e que recentemente lançaram o documentário Fonemas da Liberdade que aborda o centenário de Paulo Freire.

A seção Debates é iniciada pelo artigo Partido Comunista da Venezuela (PCV): a confluência BolivarMarx e a revolução bolivariana de Túlio Lopes que apresenta a inserção dos comunistas na luta de classes contemporânea da Venezuela, tema ainda pouco divulgado no Brasil. Marta Loula Dourado Viana aborda a ação dos comunistas no Brasil no âmbito da educação e cultura entre 1945 e 1947. O comunista peruano José Carlos Mariátegui, considerado um dos fundadores do marxismo latino-americano, é discutido por João Rafael Chió Serra Carvalho.

A psicologia de Ignácio Martín Baró, a partir de sua inserção no contexto de El Salvador, é o fundamento para a análise da violência por Mariana Lins e Silva Costa e Sonia Shima. Thiago Matias de Sousa Araújo e Amarílio Ferreira Júnior abordam as alterações do contexto educativo na Bolívia após a vitória eleitoral em 2005 do Movimiento al Socialismo - Instrumento Político por la Soberanía de los Pueblos (MASIPSP). O internacionalismo da Escola Nacional Florestan Fernandes ligada ao MST, e em especial sua articulação na América Latina, são analisados por Fábio Tomaz Ferreira da Silva e Rosana Cebalho Fernandes.

$\mathrm{Na}$ sequência temos dois artigos que articulam o tema da educação na Revolução Cubana. No primeiro, Lia Pinheiro Barbosa articula em sua reflexão os processos educativos na ilha socialista, a centralidade da alfabetização nessa experiência e o debate da agroecologia. No segundo, o pesquisador cubano Felipe de J. Pérez Cruz explora a relação entre Paulo Freire e a Revolução Cubana. A seção é finalizada por uma estimulante contribuição de Dermeval Saviani sobre as aproximações e distanciamentos da Pedagogia Histórico-Crítica com a Pedagogia da Libertação de Paulo Freire.

A seção Artigos é aberta com Hedgard Rodrigues Silva e Jorge Fernando Hermida, que trazem apontamentos importantes acerca do método de investigação e de exposição em Marx e suas implicações para a pesquisa educacional. José Salvador Almeida e Frederico Jorge Ferreira Costa apresentam um debate sobre a concepção de educação no pensamento marxiano no período de 1844 a 1848, a qual deve ser identificada a partir do estudo dos pressupostos que compõem a sua teoria. A escola única do trabalho, 
experiência implementada na União Soviética em seu primeiro momento de efervescência revolucionária, é o tema do trabalho de Diego Becker, que traz questionamentos para as reformas educacionais ocorridas no Brasil do século XXI.

Na sequência, Naara Queiroz de Melo e Melânia Mendonça Rodrigues analisam o processo de mercantilização da educação no Brasil sob a ótica da relação Estado-mercado, trazendo para o debate a relação da educação com a ideologia do Estado Regulador e do Mercado Educador. A reprodução das relações de produção capitalistas e suas expressões na educação escolar é a problemática apresentada por Paulo Henrique de Vasconcelos e Maria Cristina dos Santos. Danielle do Nascimento Rezera e Walson Lopes, com o aporte teórico da Pedagogia Histórico-Crítica, apresentam a problemática do Estado na transição do capitalismo para o socialismo/comunismo.

A seção segue com a concepção de educação e de escola contida nas propostas conservadoras "bolsolavistas" para a educação brasileira, assim como os seus fundamentos, tema desenvolvido por Lucas Carneiro Costa, Caroline Duailibi Felício, Francis Dávila Souza Costa, Débora Rezende do Carmo Azevedo. Já as autoras Ana Cristina Furtado Pereira, Neide de Almeida Lança Galvão Favaro e Priscila Semzezem apresentam o processo histórico de acesso da mulher à escolarização, especialmente ao Ensino Superior no Brasil, com suas contradições e tendências em curso.

Também com o aporte da Pedagogia Histórico-Crítica e da abordagem Crítico-Superadora, Marcos Natali e Márcia Morschbacher trazem uma reflexão sobre o conceito de brincadeira/brincar em periódicos científicos da educação física. Já Henrique Leão Coelho faz apontamentos sobre a tese da ontonegatividade da política nos textos A Sagrada Família e A Ideologia Alemã de Karl Marx.

Por fim, Rodrigo Jurucê Mattos Gonçalves discute a criação do Instituto Brasileiro de Filosofia (IBF), responsável pela publicação da Revista Brasileira de Filosofia (RBF), no contexto da História do Brasil republicano entre as ditaduras do Estado Novo e a Militar (1946-1964), e a contribuição de seu líder, Miguel Reale, para a elaboração do pensamento autocrático e pós-integralista. E, Raphael Carmesin Gomes e Damião Bezerra Oliveira apresentam uma importante análise acerca da historicidade da Extensão Universitária nas universidades mercantis enquanto espaço de estratégia ideológica da Terceira Via, no qual se reforça o consenso para a consolidação da hegemonia burguesa.

$\mathrm{Na}$ seção Clássicos temos o texto, traduzido por Adrinao Nascimento, que traz a intervenção política do intelectual peruano Manuel González Prada (1844-1918) no 1º de maio de 1905 na Federação de Operários Padeiros Estrela do Peru. O texto aborda a relação entre pensamento e ação, trabalho manual e intelectual, na perspectiva de luta da classe trabalhadora. Anos mais tarde, já na década de 20 do século passado, o revolucionário peruano José Carlos Mariátegui animaria a experiência de educação proletária que ficou conhecida como Universidad Popular Gonzalez Prada. Também nessa seção temos o que talvez seja o último ensaio de Bolivar Echeverria publicado pela primeira vez em 2010. O intelectual de origem equatoriana e naturalizado mexicano foi professor emérito da Universidade Nacional Autônoma do México. Nesta reflexão potente intitulada Ámerica Latina: 200 anos de fatalidade, gentilmente traduzida por Thays Fidelis. 
Por fim, ainda na seção Clássicos, apresentamos aos leitores e leitoras da revista uma entrevista de Paulo Freire feita por Esther Pérez e Fernando Martínez Heredia, dois dos maiores intelectuais cubanos no debate da cultura e educação da Revolução Cubana, publicada originalmente na Revista Casa de Las Américas, no 164, no ano de 1987. O texto que reproduzimos aqui é baseado na versão que integra o livro Diálogos com Paulo Freire de Paulo Freire, Esther Pérez e Fernando Martínez Heredia publicada pela Editoral Caminos no ano de 1997 e disponível no Acervo Educador Paulo Freire no seguinte endereço digital: http://acervo.paulofreire.org:8080/xmlui/.

A seção Resenhas é, neste número composta por quatro escritos.. Nelma Bernardes Vieira nos apresenta o livro Trabalho docente sob a lógica privatista empresarial: a busca pela força de trabalho a serviço de um projeto hegemônico fruto do trabalho de doutorado da autora Amanda Moreira da Silva. Ainda no debate sobre a formação de professores Maria de Fátima Rodrigues Pereira nos brinda com um escrito sobre o potente livro Para a crítica dos fundamentos da formação de professores no Brasil. $\mathrm{O}$ problema da prática ${ }^{6} \mathrm{da}$ autora Elza Margarida de Mendonça Peixoto. O número ainda conta com a resenhas escrita por Mike Ceriani de Oliveira Gomes sobre um Livro do Frei Beto intitulado Por uma educação crítica e participativa . O número é encerrado com um escrito de Marcia Salete Wisniewski Schaly e Anita Helena Schlesener tratando sobre o livro A luta em defesa da educação pública no Brasil (1980-1996): obstáculos, dilemas e lições à luz da história da autora Lucelma Braga

Encerramos esse dossiê com a expectativa de que ele contribua para ampliação de um debate cada vez mais anticolonial na perspectiva do marxismo e, portanto, menos eurocentrado, em direção a uma concepção de educação que cada vez mais aponte para um processo revolucionário que finalmente fará com que as veias da América Latina parem de sangrar.

A organizadora e os organizadores, 27 de dezembro de 2021.

\section{Referências}

MARIÁTEGUI, José Carlos. Defensa del marxismo. Lima: Editora Amauta, 1988 [1929].

BENJAMIN, Walter, Tesis sobre la historia y otros fragmentos. Edição, tradução e introdução de Bolívar Echeverría. México DF: UAM/ITACA, 2008. 


\section{Notas}

${ }^{1}$ Professor da Universidade Federal da Integração Latino-americana (UNILA). Doutor em Economia Política Internacional pela Universidade Federal do Rio de Janeiro (UFRJ). Mestre em Estudos Latino-americanos pela Universidad Nacional Autónoma de México (UNAM) e graduado em Ciências Econômicas pela Universidade Federal de Santa Catarina (UFSC). Membro do Instituto de Estudos Latino-Americanos (IELA-UFSC). Integrante do Grupo de Trabalho "Crisis y Economía Mundial", dentro do Programa 2019-2022 de Grupos de Trabalho do Conselho Latino-americano de Ciências Sociais (CLACSO). Lattes; http://lattes.cnpq.br/2601183021071758 . ORCID: https://orcid.org/0000-0002-2161-6504E-mail: fernandoprado@gmail.com

2 Possui graduação em Formação de Psicólogo pela Universidade Estadual Paulista Júlio de Mesquita Filho (2007), graduação em Licenciatura Plena em Psicologia pela Universidade Estadual Paulista Júlio de Mesquita Filho (2006), mestrado em Educação Escolar pela Universidade Estadual Paulista campus de Araraquara (2011) e doutorado em Programa de Educação Escolar pela Universidade Estadual Paulista campus de Araraquara (2016). Lattes: http://lattes.cnpq.br/2726281356078379 ORCID: https://orcid.org/0000-0003-4045-7040.E-mail: gisellemagalhaes@ufscar.br

3 Possui graduação em Licenciatura em Ciências Biológicas pela Universidade Estadual de Campinas (2007),Especialização em Formação de Educadores Ambientais pela Universidade Estadual de Campinas (2011) e Mestrado em Educação da Universidade Federal de São Carlos no campus Sorocaba na linha de Teorias e Fundamentos da Educação. Tem experiência nas áreas de Teoria e Fundamentos da Educação, Educação e Meio Ambiente e Educação e Movimentos Sociais,Relação entre Teoria e Prática Educativa. Lattes: http://lattes.cnpq.br/6466684523583420 . ORCID: https://orcid.org/0000-0002-0332-1470

${ }^{4}$ Possui graduação em Química pela Universidade Federal da Bahia (UFBA), mestrado e doutorado pelo programa de pós graduação em Ensino, Filosofia e História das Ciências da UFBA Atualmente é professor adjunto da Universidade Federal da Bahia.É professor permanente no Programa de Pós-Graduação em Ensino, Filosofia e História das Ciências da UFBA/UEFS. É lider do grupo de pesquisa ENCONCIENCIAs ( Grupo de Pesquisa em Ensino Concreto de Ciências). Lattes: http://lattes.cnpq.br/5284620682449345 .Orcid; http://orcid.org/0000-0002-6620-2989 .E-mail: helioneto@ufba.br ${ }^{5}$ Para saber mais: https://theliteracyproject.org/ 